\title{
A EDUCOMUNICAÇÃO E AS NOVAS PRÁTICAS JORNALÍSTICAS: um campo de interseções
}

\section{EDUCOMMUNICATION AND THE NEW JOURNALISTIC PRACTICES: field intersections}

\author{
Rosa Maria DALLA COSTA ${ }^{1}$; Aline Tainá Amaral HORN²
}

Resumo: Este artigo propõe reflexões sobre a atuação do jornalista em projetos de comunicação e educação institucionais. Parte-se do entendimento que a educomunicação é um campo do conhecimento que estabelece interseção com o mundo de trabalho do jornalista, tendo em vista que são crescentes os projetos educomunicativos, de responsabilidade social, que emergem dentro das corporações de comunicação. O referencial teórico baliza-se na área de intervenção produção midiática, conceito proposto por Soares (2014), que abarca ações e programas produzidos pelas mídias a partir do parâmetro educomunicativo. Discute-se o paralelo que se estabelece entre ações educomunicativas e as novas práticas jornalísticas, sem perder de vista que o jornalista tem imbuído no seu exercício profissional o compromisso com a educação.

Palavras-chave: Educomunicação; jornalismo; novas práticas jornalísticas.

Abstract: This article proposes reflections about the journalist's way to work in communication and education projects. The educommunication is a field of knowledge that establishes an intersection with the journalist's work world, considering that are increasing the educommunication institutional projects of social responsibility, emerging within the communications corporations. The theoretical is based in the media production area, concept proposed by Soares (2014), which includes actions and programs produced by media from educommunication parameter. It discusses the parallel established between educommunication actions and new journalistic practices, considering that the journalist has imbued in their professional practice the commitment to education.

Keywords: Educommunication; journalism; new journalistic practices.

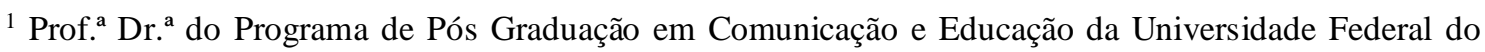
Paraná (PPGCOM/PPGE). Jornalista (MT 16792/65/54) e Advogada (OAB/PR 67.414). Doutora em Sciences de l'Information et de la Communication (Université de Paris VIII, 1999) e Pós-Doutora em Comunicação pela Maison des Sciences de l'Homme - Paris Nord (2008). E-mail: rmdcosta@uol.com.br

2 Jornalista e mestranda do Programa de Pós Graduação em Comunicação da Universidade Federal do Paraná (PPGCOM), linha de pesquisa Comunicação, Educação e Formações Socioculturais. Atualmente integra o grupo de pesquisa internacional sobre as novas práticas jornalísticas, decorrente de um convênio entre o programa JADN - Journalisme à l'heure du numérique - Université Lumière Lyon 2 (França) e CLICK-UFPR/INCOM-UTP. E-mail: hornaline@gmail.com
} 


\section{míDiA \\ e DiAno}

\section{Introdução}

É possível notar, nos dias de hoje, o estreitamento cada vez mais acentuado entre os campos da Comunicação e Educação por meio do desenvolvimento de projetos idealizados por iniciativas do governo, terceiro setor e organizações de variados segmentos. Ter o entendimento dos avanços e das limitações de cada uma dessas áreas do conhecimento é essencial à compreensão do universo de suas possibilidades de interface. Na Comunicação, o jornalista, frente às novas formas de interação com o público, aparatos tecnológicos avançados e questões de âmbito institucional e de mercado, é desafiado a todo o momento a se adequar às novas demandas da profissão, "reinventando" um novo modo de fazer jornalismo. Enquanto que a Educação, apesar dos avanços no que diz respeito às metodologias de ensino e uso de tecnologias em sala de aula, ainda apresenta certa resistência na utilização com/para/pelos meios na escola quando retira, por vezes, do aluno, seu potencial de produção de conhecimento, mesmo diante dos novos formatos vigentes de aprendizagem.

Entendendo que pensar a relação entre a comunicação e educação e seus papéis como difusoras de valores hegemônicos é indispensável à configuração das sociedades atuais e, que é fundamental compreender como os profissionais, em particular, os jornalistas, atuam em propostas com iniciativas que buscam aproximar estas áreas do saber, este artigo propõe discorrer sobre a aproximação entre a comunicação e educação, implicações da educomunicação e perspectivas de atuação do jornalista nas sociedades contemporâneas.

A partir do entendimento que a educomunicação é um campo do conhecimento que apresenta interseções com o mundo de trabalho do jornalista, tendo em vista que são crescentes os projetos institucionais educomunicativos, de responsabilidade social, que emergem dentro das corporações de comunicação, propõe-se discutir o paralelo que se estabelece entre as novas práticas jornalísticas e ações educomunicativas dentro das organizações. O referencial teórico principal baliza-se nas abordagens da Educomunicação, a destacar, a área de intervenção produção midiática, conceito proposto por Soares (2014) para indicar ações e programas produzidos pelas mídias a partir do parâmetro educomunicativo. 


\section{A Educomunicação: uma nova área do conhecimento do século XXI}

Não é de hoje a relação estabelecida entre os campos de comunicação e educação. Segundo Soares (2011), na América Latina, as primeiras experiências que envolveram estes campos, aconteceram no período de 1945 a 1964, como resistência aos regimes ditatoriais e, se fundamentaram mais na pedagogia freireana e nos movimentos populares (centros de educação popular, igrejas, movimentos de educação de base) do que no sistema educacional formal. Para o autor a proposta desses movimentos era problematizar a presença dos meios de comunicação na vida cotidiana das comunidades e instigar uma visão crítica, por meio de dispositivos expressivos e dialógicos.

No Brasil, esta realidade não foi diferente. Conforme afirma Dalla Costa (2008, p. 98), as investigações sobre as inter-relações entre os campos comunicação e educação "ganham consistência a partir da segunda metade do século XX, em especial após a popularização das emissoras de rádio e de televisão e a criação dos cursos de Comunicação Social". Desde então, a implantação de projetos na área da educação para a comunicação tornou-se um importante desafio, tendo em vista que a relação entre estes campos do saber, conforme afirma Soares (2011), se deu por meio de contribuíções teórico práticas de Célestin Freinet e Paulo Freire, filósofos da educação e, de Jesús Martín-Barbero e Mário Kaplún, autores da comunicação, que tinham seus referencias teóricos embasados na formação crítica e dialógica do sujeito. Já na Europa, particularmente na França, o surgimento de projetos de comunicação e educação têm origens e propósitos diferenciados:

No Brasil, são criados no âmbito dos movimentos sociais e populares e têm inicialmente o objetivo de conscientizar a população sobre as possibilidades de manipulação de opiniões da mídia de uma maneira geral. Na França, são criados nas escolas ou nas televisões como propostas de participação democrática, ainda que, segundo Jacquinot-Delaunay (2006), encontrem algumas resistências no âmbito acadêmico. (DALLA COSTA, 2008, p. 3)

Portanto, dadas às divergências de propostas de comunicação e educação na América Latina e Europa, vale destacar que em território latino americano, nos dias de hoje, conforme observa Citelli (2002, p. 153), a relação entre estas áreas do conhecimento tem mobilizado esforços de várias entidades governamentais e não 
governamentais - instituições acadêmicas, religiosas, organizações da sociedade civil e movimentos populares - que buscam implantar ações com o objetivo tanto de pesquisar e refletir teoricamente sobre a inter-relação comunicação/educação como "também de implementar novas metodologias e práticas capazes de formar competências para a realização de produtos culturais apoiados nas linguagens dos meios". Nas corporações de comunicação, o cenário não é diferente.

Projetos de comunicação e educação têm crescido a cada ano dentro das organizações. O Instituto GRPCom ${ }^{3}$ (Grupo Paranaense de Comunicação), por exemplo, idealizou o Ler e Pensar, Televisando e 98 FM nas escolas ${ }^{4}$, projetos realizados em parceria com a RPC TV (Rede Paranaense de Comunicação), Gazeta do Povo ${ }^{5}$ entre outros veículos pertencentes ao mesmo grupo de comunicação do qual fazem parte. Tendo em vista que esses projetos são também de responsabilidade social, ressalta-se:

[...] o mundo empresarial, sob pressão das demandas advindas da aplicação do conceito de responsabilidade social, tem demonstrado interesse em contar com consultores que contribuam para melhorar processos de relacionamento tanto com seus públicos externos quanto com seus próprios funcionários, através de práticas educomunicativas que superem uma visão mais superficial de marketing social. (SOARES, 2011, p. 62)

Segundo Ribeiro (2012, p. 87) as empresas têm intensificado o apoio a programas sociais e ao desenvolvimento de projetos voltados a uma causa. "Tais práticas parecem estar cada vez mais integradas ao conjunto de estratégias corporativas que regem o negócio, deixando de ser uma atividade de importância secundária para a alta administração". Atenta que, ainda assim, existem poucas pesquisas na área de interface da comunicação e educação, o que "dificulta o entendimento do campo e impossibilita as organizações de fazerem uso dessas ferramentas ao seu favor e a favor dos públicos com os quais elas se relacionam" (RIBEIRO, 2012, p. 81).

\footnotetext{
${ }^{3}$ Oscip (Organização da Sociedade Civil de Interesse Público).

${ }^{4}$ Disponível em: 〈http://www.institutogrpcom.org.br/educomunicacao $>$. Acesso em: 20 jul. 2015.

${ }^{5}$ Jornal impresso do estado do Paraná.
} 
Nesse recorte de estudo, chama-se atenção às perspectivas conceituais da Educomunicação ${ }^{6}$, nova área de intervenção com certa autonomia em relação aos tradicionais campos da educação e da comunicação. Soares (2011, p. 36), conceitua esse campo do saber como um conjunto de ações voltadas ao planejamento e implementação de práticas destinadas a criar e desenvolver "ecossistemas comunicativos, abertos e criativos em espaços educativos, garantindo, dessa forma, crescentes possibilidades de expressão a todos os membros das comunidades educativas".

Embora Soares (2011, p. 37) reconheça que o diálogo não seja estabelecido pela tecnologia adotada, mas sim pela construção de modalidades abertas e criativas de relacionamento entre os sujeitos, ressalta que a educomunicação precisa ser construída intencionalmente, por meio de ações inclusivas, democráticas, criativas e midiáticas. Coloca-se em destaque esta última categoria por constituir ações que valorizam as mediações possibilitadas pelos veículos de comunicação, que têm como seus protagonistas, os jornalistas.

As ações que levam às práticas educomunicativas constituem as denominadas "áreas de intervenção" (SOARES, 2014, p. 138), a destacar: educação para a comunicação (volta-se para o estudo do lugar dos meios de comunicação na sociedade e caracteriza-se pela implementação de projetos de mídia-educação); a expressão comunicativa através das artes (formas de manifestação artística na comunidade educativa); a mediação tecnológica nas práticas educativas (caracteriza-se pelo acesso e uso democrático da tecnologia na cultura escolar); pedagogia da comunicação (referese às ações na educação por meio de projetos da escola); gestão da comunicação nos espaços educativos (volta-se para o planejamento e execução de projetos referentes às demais áreas de intervenção, no intuito de promover espaços de convivência e uso das tecnologias); reflexão epistemológica (trata-se do estudo do próprio fenômeno constituído pela inter-relação entre educação e comunicação) e, por fim, a produção midiática (ações, programas e produtos da mídia elaborados a partir da educomunicação), área da qual se ancoram as reflexões levantadas nesse artigo.

\footnotetext{
${ }^{6}$ Idealizada pelo professor Ismar de Oliveira Soares, nasceu no Núcleo de Comunicação e Educação da Universidade de São Paulo (NCE-USP) e tornou-se licenciatura, nessa mesma universidade, em 2009.
} 
Resgatando aqui o conceito de Martín-Barbero (2014), vive-se hoje numa sociedade do conhecimento compartilhado e da aprendizagem contínua, onde os lugares para aprender são todos, o que de certa forma descaracteriza a escola como única instituição detentora do saber responsável pela formação do indivíduo e, acentua o compromisso de outras instituições educativas "informais". É o caso dos veículos de comunicação. Mais livres e desprendidos da posição verticalista na relação professor/aluno (ainda predominante na maioria das escolas), se configuram como um espaço privilegiado de possibilidades de aprendizado, conforme observa Baccega (2009, p. 22), dividindo as funções antes destinadas somente à escola:

\footnotetext{
Os meios de comunicação são hoje um novo espaço do saber, ocupando parte do lugar que antes era destinado apenas à escola. Aparece também como lugar de publicização, a qual, no mais das vezes, é indispensável para obtenção de êxito em nossos objetivos. O que não deu na televisão, não aconteceu. (BACCEGA, 2009, p. 27)
}

Segundo Orozco Gómes (1997, p. 58) fala-se com certa familiaridade que os meios de comunicação são uma "escola paralela", ou seja, uma escola "sem licença para ensinar que se instalou nas sociedades contemporâneas, de maneira definitiva, e que ameaça as funções e objetivos de outros agentes e instituições já legitimados". Se na dimensão educativa o aprendizado pode se constituir fora do modelo escolar, frente às mídias, cabe aos jornalistas, do lado da produção, a responsabilidade de "oferecer formas com que se contrapor ao isolamento e a incerteza dos indivíduos, possibilitando vínculos culturais para os diversos grupos em que se fragmenta a sociedade" (MARTINBARBERO, 2014, p. 132). Portanto, propõe-se chamar atenção justamente para o importante papel exercido por esses profissionais para que ações educomunicativas possam de fato ser bem sucedidas, aliadas as novas práticas jornalísticas, vigentes nessa segunda década do século XXI.

\section{As novas práticas jornalísticas e as ações educomunicativas: um campo de}

\section{interseções}

O jornalista dos dias de hoje já não é o mesmo do século passado. Com o advento da internet, particularmente, a partir de meados dos anos 2000, observa-se uma série de mudanças no estatuto da profissão do jornalista, como, por exemplo, a maior interação 


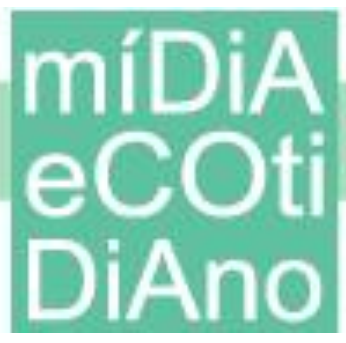

com o público, o desenvolvimento contínuo de novas competências técnicas para lidar com as tecnologias e a maior exigência em ampliar conhecimentos multidisciplinares, para dar conta desse turbilhão de dados on-line. Tudo isso, em um tempo cada vez mais acelerado.

Frente às mudanças imediatas vigentes nas sociedades, compreender a configuração do jornalismo dos dias de hoje, é também, refletir sobre as mudanças do indivíduo e de toda a trama cultural. Haroche (2008, p.123) faz uma releitura do conceito de "liquidez", termo idealizado por Bauman no livro "Modernidade Líquida" (2001) e, atenta que as sociedades contemporâneas, sob o impacto da globalização, tendem a se transformar de maneira contínua, balizadas por valores efêmeros e superficiais. Por consequência, essas configurações do mundo de hoje afetam o modo de fazer jornalismo, que se recicla e se reinventa a cada dia. Ou seja, atingem diretamente o trabalho do jornalista, que não só como representante do interesse público, mas também como sujeito pós-moderno, necessita acompanhar e se adaptar a essas transformações culturais. Se o jornalista apreende as mediações, isto é, tudo aquilo que influencia a maneira como o indivíduo vai receber e reelaborar as mensagens que o atingem, ele, por sua vez, reelabora o seu exercício profissional e, à medida que se transforma, o seu papel também muda perante a sociedade. Portanto, é inegável que a compreensão do modo de fazer o jornalismo (incluindo suas mutações e permanências) perpasse pela análise da conjuntura cultural contemporânea (cenário pós-moderno) e pelos fenômenos de comunicação.

Nos dias de hoje, é possível notar os efeitos da globalização na formação das culturas. Nunca na história da humanidade se teve tanta facilidade de acesso à informação e nunca se produziu tanto conhecimento, como atualmente. E isso se deve a interatividade, característica elementar que pauta as relações sociais e de comunicação e, que no século XXI, transformou-se no pilar da vida em sociedade. A interação, logicamente, sempre existiu, porém, adquire, nos tempos atuais, diferentes formatos, frente às novas formas de pensar, agir e sentir em uma cultura digital que faz emergir uma espécie de "esquizofrenia" entre o mundo virtual e o real. 


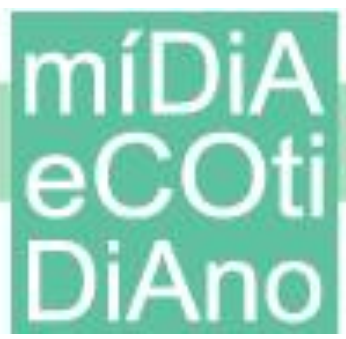

No mundo de trabalho do jornalista, a interatividade faz parte da rotina da profissão e dos valores institucionais dos veículos de comunicação. O Jornal Nacional, por exemplo, telejornal mais assistido nos lares brasileiros, com $56,4 \%{ }^{7}$ da preferência do público, inaugurou em 2015, no aniversário de 50 anos da TV Globo, um novo formato: enquadramentos de tela diferenciados, linguagem mais informal, espaço para breves comentários e opiniões dos apresentadores, telas maiores que simulam a presença dos correspondentes internacionais na própria bancada no jornal etc. Além dos recursos modernos e tecnológicos, o rompimento das formalidades do jornalismo padrão "sério", demonstra que o novo modo de fazer jornalismo está sendo emplacado a partir da tentativa de gerar uma interação ainda maior com o público, de forma mais pessoal e imediata.

As novas práticas jornalísticas, mais do que associadas as recentes interfaces tecnológicas, estão diretamente relacionadas com as novas formas de interação com o público, que nos dias de hoje, longe de ser somente sujeito-receptor, é também emissor, produtor de conteúdo e, está cada vez mais em "contato" com os jornalistas, compartilhando fotos, vídeos e informações na sua vida diária (trânsito, clima etc) em tempo real. Frente a um público mais ativo e participativo, cabe ao jornalista desenvolver alternativas colaborativas de coleta e formatação de conteúdo noticioso. Quando oferece ao indivíduo um espaço na mídia para ter voz, ou seja, falar e ser ouvido, o jornalista, particularmente, por meio de projetos que aliam a comunicação e a educação, tem uma maior possibilidade de contribuir para a criação de ecossistemas comunicativos, ambientes que oportunizem o diálogo e a reflexão, por meio das ferramentas da comunicação (SOARES, 2011, p. 44).

Atualmente, já existem programas de responsabilidade social e ações educomunicativas consolidadas institucionalmente, porém, conforme afirma Ribeiro (2012, p. 81), observa-se que as empresas aderentes têm como objetivo principal fortalecer a imagem organizacional a uma perspectiva de comprometimento,

\footnotetext{
${ }^{7}$ Meta Pesquisas de Opinião Brasileira. Disponível em: 〈http://www.metapesquisa.com.br $>$. Acesso em: 7 jun. 2015.
} 


\title{
míDiA

cooperação, interesse público e transformação social. Ou seja, não necessariamente de fato estão alinhadas à proposta educomunicativa:

\begin{abstract}
As organizações têm dificuldade de eleger focos de atuação e utilizar competências organizacionais para obter maiores eficiência e eficácia das ações sociais promovidas e elegem os projetos na área de educação como prioridade sem ter um conhecimento teórico-metodológico da interface e de como podem responder as demandas e necessidades da organização e de seus públicos. (RIBEIRO, 2012, p. 87)
\end{abstract}

Para que práticas educomunicativas de fato sejam consolidadas nas organizações, é fundamental a implementação de ações conjuntas entre profissionais da educação, educomunicadores e jornalistas. Atenta-se, por outro lado, que quando se fala em projetos de comunicação e educação, geralmente, o jornalista aparece de forma apagada, como coadjuvante. Ainda não se associa a figura desse profissional como mediador de ações educomunicativas, agente transformador que integra todo o processo de aprendizagem e formação dos sujeitos.

Como as práticas educomunicativas não acontecem espontaneamente dentro das organizações (SOARES, 2011, p. 37), o engajamento do jornalista em ações que visam a criticidade do público, o fomento ao diálogo, assim como o maior aprofundamento sobre a proposta da educomunicação, em muito depende da iniciativa das próprias corporações em não somente implementar tais práticas no contexto empresarial, mas também, priorizar o investimento na formação continuada em mídia-educação desses profissionais da comunicação, assim como oportunizar no ambiente de trabalho do jornalista a interação com os educadores, por meio do compartilhamento de conhecimentos e experiências da cultura escolar.

É o que observa Carvalho (2005, s/p) ao afirmar que a educomunicação aplicada ao mundo organizacional surge como o meio mais adequado para fazer das organizações, ecossistemas comunicativos, tendo como seus principais campos de ação: a (re)afirmação ou (re)construção de uma identidade corporativa sólida com a participação ativa dos colaboradores; a formação dirigida às pessoas da empresa com implicação prática no dia-a-dia da organização; a integração entre colaboradores e empresa, através de unidades educativas; e ações que busquem formar os funcionários 


\section{míiA \\ eco DiAno}

como usuários críticos, pensadores e arquitetos dos meios de comunicação e das tecnologias da informação.

Apesar de propostas educomunicativas estarem despontando nos veículos de comunicação, Soares (apud VERONEZE, 2008, s/p) atenta que a educomunicação ainda não é realizada plenamente nas organizações "devido à existência de hierarquia e expectativa estabelecidas pelas empresas com relação ao comportamento dos funcionários". Ou seja, há fatores de ordem institucional que inviabilizam a adesão bem sucedida de projetos de comunicação e educação, como: 1) a ausência de uma gestão horizontal, que oportunize a autonomia do funcionário, assim como o compartilhamento de experiências e expertises na relação entre colegas de trabalho e chefes; 2) não agregação de valor a propostas educomunicativas; 3) falta de investimentos; 4) dificuldades afins à própria rotina de trabalho, ao modo de operar as funções das redações, sejam elas de TV, rádio ou web. Por vezes, o dia a dia de trabalho impõe algumas restrições ao jornalista, como o cumprimento de metas de produtividade, tempo limitado para a produção das notícias e, até mesmo adequação às novas tecnologias em um tempo cada vez mais reduzido.

Diante das mudanças afins a rotina de trabalho e novos rumos do fazer jornalismo, o jornalista está literalmente num "fogo cruzado". Para Grohmann (2013, p. 246) esse profissional encontra na sua prática profissional o que não quer, ou seja, valores e práticas que não reiteram os valores deontológicos: “(...) o jornalista se ilumina com esses valores, no entanto, não são esses valores que orientam a atividade real de trabalho". Um exemplo claro disso, conforme aponta Baccega (2003, p. 35), é quando o jornalista cobre um evento para a televisão e tem pouco tempo para pensar sobre o que significa o fato que ele está cobrindo. Para a autora, é preciso que o jornalista consiga perceber e relacionar as várias partes que compõe o acontecimento e, isso exige uma preparação prévia muito intensa, já que no local da cobertura não haverá tempo suficiente para absorver e aprender tudo. "Só com conhecimento ele será capaz de contextualizar o que está ocorrendo, para que possa construir um discurso, um texto que percorrerá o mundo. Caso contrário, a notícia não se sustentaria” (BACCEGA, 2003, p. $35)$. 
O compromisso do jornalista como interlocutor dos fatos que ganham visibilidade nos meios de comunicação, torna-se ainda maior, tendo em vista que o público interpreta somente aquilo que chega ao seu conhecimento, ou seja, aquilo que foi escolhido no âmbito da produção, levando em conta vários aspectos, sobretudo a orientação da empresa detentora daquela mídia (BACCEGA, 2003, p. 26).

Se é verdade que o receptor (enunciatário/enunciador) mobiliza seu universo cultural para interpretar o que aparece nos meios de comunicação, seja de que gênero for, também é verdade que temos de levar em conta em nossas reflexões a mediação, o filtro que antecede o que ele está vendo, ouvindo ou lendo: a mediação no campo da produção. (BACCEGA, 2003, p. 26)

No campo da produção, Grohmann (2013, p. 246) ressalta que o jornalista vai muito além da técnica, pois é capaz de “'dissecar as informações” e descobrir as 'mensagens subliminares' onde se escondem os juízos de valor'. Para o autor as relações dialógicas têm como referência os valores humanistas e ideias iluministas, no qual o jornalista se coloca como um intelectual que tem papel de "guardião da palavra" e tem por "missão" informar e mostrar a "verdade" a população:

\begin{abstract}
Nesse caso o jornalista como receptor, essa missão de revelar a verdade é destinada a si mesmo e a quem ele se relaciona cotidianamente. São esses valores que dão sustentação a deontologia do profissional do jornalismo. Sem eles, o jornalismo e o jornalista perde sua função social e iguala-se ao publicitário e as relações públicas, pois perde seu compromisso com o que se considera 'espaço público', o 'interesse público', o 'bem-comum', para passar a atuar na esfera dos interesses privados, de instituições e pessoas de caráter privado. (GROHMANN, 2013, p. 246)
\end{abstract}

Nonato (2013, p. 145), por sua vez, sinaliza que cabe ao jornalista, como um mediador, ser "capaz de atuar no campo da comunicação de maneira integrada, articulando diferentes mídias e linguagens da comunicação a partir de uma sólida formação humanística”. Já Fígaro (2013, p. 14) alerta que cabe ainda a este profissional atuar em multiplataformas, ter domínio sobre aspectos estéticos e de conteúdo, ter "noções de marketing e de administração, visto que se prioriza a visão de negócios/mercadoria já inserida no produto cultural, por meio do tratamento dados as pautas e a segmentação do público".

Esses apontamentos remetem a afirmativa de Marcondes Filho (2002, p. 53) ao conceber o jornalismo como uma atividade múltipla: 
Um jornalismo diário de um grande matutino é muito diferente do jornalismo semanal, de uma revista especializada, de um boletim de assessoria de imprensa ou de um jornal sindical ou de bairro. Mas o canal também difere: fazer notícias para o jornal das 20 horas é diferente de fazer uma reportagem como enviado especial do outro lado do planeta, organizar um documentário, um reality-show, conduzir uma entrevista, e todos estes diferem muito do jornalismo de rádio ou da imprensa escrita. E todos são jornalistas. (MARCONDES FILHO, 2002, p. 53)

Esse aumento do número de atribuições do jornalista, reflexo da expansão das redes, da globalização, das novas formas de se relacionar com o mundo e com as pessoas, da interatividade, da convergência digital, entre outros, são alguns dos atributos que pautam as novas práticas jornalísticas em pleno século XXI: produção colaborativa das notícias (levando em conta a participação ativa do público), atuação em multiplataformas, visão de negócios e de marketing, foco na internacionalização e, ainda, participação em ações educomunicativas por meio de projetos institucionais de comunicação e educação. Em relação a esse último, Soares (apud VERONEZE, 2008, $\mathrm{s} / \mathrm{p})$ propõe que as empresas se aproximem das práticas educativas por meio de uma negociação "que pode ser feita na medida em que a empresa esteja aberta para um diálogo cultural, permitindo que os funcionários escolham metodologias de trabalho e tenham espaço para expressões culturais".

Esses apontamentos constituem o pano de fundo que ilustra a interseção entre as novas práticas jornalísticas e as ações educomunicativas, as quais têm adquirido cada vez mais espaço nas corporações de comunicação. Diante da compreensão de que a educomunicação é consolidada de forma intencional, chama-se atenção aqui para o que Soares (2011, p. 37) aponta como aspectos necessários à construção dos ecossistemas comunicativos: clareza conceitual, planejamento, acompanhamento e avaliação. Ou seja, o mapeamento de ações institucionais que contemple tais aspectos por meio de projetos educomunicativos (desde sua concepção até sua avaliação dos resultados) e, que simultaneamente, leve em conta as mudanças latentes no mundo de trabalho do jornalista, indica uma maior possibilidade de aderência e efetiva incorporação de propostas com iniciativas educomunicativas dentro das organizações. 


\section{Conclusão}

Diante da proposta de compreender as interseções estabelecidas entre as novas práticas jornalísticas e ações educomunicativas, pode-se afirmar que há uma emergência para que programas de comunicação e educação sejam desenvolvidos pelos veículos de comunicação, incluindo, portanto, a participação ativa dos jornalistas, por meio da área de intervenção da educomunicação denominada produção midiática. Evidencia-se que o engajamento do jornalista nesses projetos de responsabilidade social leva a construção dos ecossistemas comunicativos, desde que a corporação de comunicação da qual faça parte integre às suas ações internas tais propostas à rotina de trabalho desse profissional. Sem apoio institucional, o jornalista terá poucas chances de desenvolver ações que efetivamente se aproximem da proposta educomunicativa.

Ainda que de forma incipiente, as novas práticas jornalísticas contemplam algumas ações voltadas à Educomunicação, por outro lado, é possível observar que a dicotomia entre a comunicação e educação, latente no mundo de trabalho do jornalista, se acentua frente às restrições profissionais que limitam a sua atuação em projetos institucionais que propõem a interface dessas duas áreas do conhecimento.

Este artigo, longe da pretensão de chegar a respostas fechadas, trouxe a tona reflexões sobre a possibilidade de que ações educomunicativas sejam incorporadas às novas práticas jornalísticas. Para dar continuidade a esse estudo, tem-se como ponto de partida o entendimento de que a comunicação e educação constituam juntas "um novo espaço teórico capaz de fundamentar práticas de formação de sujeitos conscientes" (BACCEGA, 2009, p. 21), mas, por outro lado, atenta-se para a necessidade de que as empresas superem a concepção de que "ações de responsabilidade social são apenas aparentemente 'sociais' (...) preocupadas mais com a visibilidade e lucratividade do que com a transformação social" (RIBEIRO, 2012, p.91).

\section{Referências}

BACCEGA, M. A. Comunicação/educação e a construção de uma nova variável histórica. In. Comunicação \& Educação. São Paulo: CCA/ECA/USP/Paulinas, a. 14, n. 3, set./dez. 2009, pp. 19-28. 
. Televisão e Escola, uma medição possível? São Paulo: Editora Senac São Paulo, 2003.

CARVAlHO, P. M. Educomunicação e a Reinvenção da empresa do século XXI. Disponível em: <http://www.rh.com.br/Portal/Comunicacao/Artigo/4002/ educomunicacao-e-areinvencao-da-empresa-do-seculo-xxi.html>. Acesso em: 01 set. 2015.

CITELLI, A. Comunicação e Educação: Aproximações. In: BACCEGA, M. A. (Org.). Gestão de Processos Comunicacionais. São Paulo: Atlas, 2002, pp. 101-111.

DALlA COSTA, R. M. Estudos de Recepção: uma metodologia de análise dos meios de comunicação e a cultura escolar. In: SCHMIDT, M. A.; GARCIA, T. M. B.; HORN, G. B. Diálogos e Perspectivas de Investigação. Ijuí: Unijuí, 2008, pp. 95 -119.

FIGARO, R.; GROHMANN, R.; NONATO, C. As mudanças no mundo do trabalho do jornalista. São Paulo: Atlas, 2013.

HAROCHE, C. A condição sensível: formas e maneiras de sentir no ocidente. Rio de Janeiro: Contra Capa, 2008, pp. 123-226.

MARCONDES FILHO, C. M. A Saga dos cães perdidos. 2 ed. São Paulo: Hacker Editores, 2002.

MARTÍN-BARBERO, J. A comunicação na educação. São Paulo: Contexto, 2014.

META PESQUISAS DE OPINIÃO BRASILEIRA. Disponível em: <http://www.metapesquisa.com.br>. Acesso em: 7 jun. 2015.

OROZCO GÓMES, G. Comunicação \& Educação: história e imagem no tempo da TV artesanal. São Paulo: Editora Moderna, 1997, pp. 57-68.

RIBEIRO, R. R. A Educomunicação como alternativa para criação de ecossistemas comunicativos nas organizações: uma análise do Programa "Veja na Sala de Aula". In: Comunicação \& Informação, UFG, v. 15, n. 2, jul./dez. 2012, pp. 80-96.

SOARES, I. O. Educomunicação - conceito, o profissional, a aplicação. São Paulo: Paulinas, 2011.

Construção de roteiro de pesquisa a partir dos livros da Educomunicação. In: Comunicação \& Educação. São Paulo: Paulinas, a. 19, n. 2, jul./dez. 2014, pp. 135-142.

VERONEZE, A. Ismar Soares e a Educomunicação nas corporações: entrevista do prof. Ismar. Disponível em: <http://educomambiental.blogspot.com.br/2008/11/ismar-soares-eeducomunicao-nas.html>. Acesso em: 02 set. 2015. 